\title{
GCU
}

Glasgow Caledonian

University

University for the Common Good

\section{The effectiveness of the housing needs and demand}

\section{Manase, David; Siamuzwe, Valentah}

Published in:

International Journal of Housing Markets and Analysis

DOI:

10.1108/IJHMA-12-2018-0103

Publication date:

2020

Document Version

Author accepted manuscript

Link to publication in ResearchOnline

Citation for published version (Harvard):

Manase, D \& Siamuzwe, V 2020, 'The effectiveness of the housing needs and demand', International Journal of Housing Markets and Analysis, vol. 13, no. 2, pp. 125-141. https://doi.org/10.1108/IJHMA-12-2018-0103

\section{General rights}

Copyright and moral rights for the publications made accessible in the public portal are retained by the authors and/or other copyright owners and it is a condition of accessing publications that users recognise and abide by the legal requirements associated with these rights.

Take down policy

If you believe that this document breaches copyright please view our takedown policy at https://edshare.gcu.ac.uk/id/eprint/5179 for details of how to contact us. 


\title{
The Effectiveness of the Housing Needs and Demand Assessment (HNDA) Framework in Scottish Local Authorities
}

\begin{abstract}
Purpose

Literature reveals that local authorities in Scotland are required under the Housing (Scotland) Act 2001 to undertake housing need and demand assessment. Local authorities are required to ensure that their local housing strategies are evidenced with an assessment of housing need and demand. The Housing Needs and Demand Assessment (HNDA) framework was designed to help local authorities in Scotland provide the evidence base for local strategies. Since its introduction in 2014, there is limited literature highlighting whether or not the framework has been effective. To this end, the aim of the research in this paper was to evaluate the effectiveness of the Housing Needs and Demand Assessment (HNDA) framework as set in Scottish Local Authorities. Thus, the paper highlighted those factors that have been effective in the framework.
\end{abstract}

\section{Design/methodology/approach}

An evaluation to asses empirically the effectiveness of the HNDA framework in Scotland was conducted. The research involved the review of literature on the current Housing need and demand assessment framework in the Scotland. A measure of the effectiveness of the HNDA framework was conducted via a questionnaire survey to get practitioner's perception from 32 Scottish Local Authorities. This was conducted to advance specific features that have been effective in the Housing Needs and Demand Assessment (HNDA) framework. The features were then ranked in terms of their degree of effectiveness.

\section{Findings}

The research in this paper identifies initially findings cited in literature of effective factors that impact on the effectiveness of typical projects and contextualises them in the HNDA framework in Scotland, the HNDA framework having all hallmarks of a project. Results from this study identified effectiveness factors that have a greater influence on the HNDA framework's general effectiveness. These factors include amongst others: clearly defined and detailed scope; project monitoring and control; competent and experienced project managers; sufficient and well allocated resources.

\section{Research limitations/implications}

By examining the factors individually, it can be stated that overall and based on literature and survey, the HNDA framework as used in Scotland has largely been successful. The success however, is on a case by case basis. For example, those in remote based local authorities expressed reservations on whether some of the identified effectiveness factors in the framework were effective while those in more metropolitan or larger local authorities were more upbeat with the HNDA framework. 


\section{Originality/value}

No similar study has been carried out on effectiveness factors in the HNDA framework used in Scottish local authorities. The findings in this research therefore, contribute to literature that seeks to understand the mechanisms of an effective housing need and demand assessment in general and the HNDA framework in Scotland in particular. Overall, it contributes to the housing debate by offering a Scottish perspective. The study is a precursor to the mechanism for the housing need and demand and funding success in Scotland.

Keywords: Housing Need; Housing Demand; Project Effectiveness; Local Authority; Housing Demand Assessment, Effectiveness Factors

\section{Type: Research paper}

\section{Background}

In the year 2007, the new Scottish National Party (SNP) government pledged to expand the long term supply of housing and to support more (affordable) housing in ways such as an expansion of council house building. Later, in their 2010 housing policy discussion document "Fresh Thinking, New Ideas", the Scottish government (2010) noted that in this new environment, referring to the aftermath of the recession, that housing need and allocation of funds for housing may have to be reprioritised. The Homes Fit for the $21^{\text {st }}$ Century (2011) report mentions that housing is a key part of people's physical, economic and social fabric. The report emphasizes that getting housing "right" can contribute to the Scottish government's purpose of sustainable economic growth to enable the whole of Scotland to flourish. Also, housing, it was suggested in the report, can help achieve the country's full potential through better educational and employment opportunities, healthier lives and a more prosperous and equal society. To achieve this, the Scottish government's vision, articulated in the "strategy and action plan for housing in the next decade: 2011-2020" was to have a housing system which provides an affordable home for all. In addition, the Sottish government's vision on housing highlights the need to see improvements in the quality of people's homes, whether they own them or part own, rent privately or rent from social landlords. While such a vision is applauded, its actualisation has been hampered by various factors in the wider economy. Gibb and Leishman (2011) mention that Scottish housing has had to confront the credit crunch, housing market downturn, recession and unprecedented fiscal retrenchment at a time of rising housing need while the Scottish government is facing short and long term challenges that require more and not fewer housing resources. The recent and current Brexit uncertainties only make the realisation of the Scottish government housing vision ever more challenging. For example, Shelter Scotland (2015) mention that over the recent years, house prices and market rents have shown an upward trend, the latter have increased steadily and consistently while social rented sector has contracted and many households are struggling to access home ownership. Other events on the ground according to Shelter Scotland (2015) is that the overall house building levels are well below the peak of 2007 and continues to fall to date. At the same time, social rented stock has been depleted through demolitions and the right to buy. The changing terrain and trends in the housing sector requires innovative approaches to issues pertaining to housing. 


\section{Introduction}

With the issues outlined in the background section, the Scottish government has embarked on wide ranging welfare reforms to mitigate the situation. One of the key areas these welfare reforms have impacted on is the understanding of the need and demand of housing for many low-income households in Scotland. For example, a welfare reform such as the bedroom tax has resulted in increased demand for one-bedroomed properties (Shelter Scotland, 2015). Shelter Scotland (2015) also state that the number of the aging population is growing at a steady rate, as is the general Scottish population. Therefore, understanding the needs and nature of demand for housing has become an ever more important issue to the Scottish governments' housing vision realisation.

In addition, in recent years, there has been a sharp decline in housing construction in Scotland and across the UK due to the economic down turn and now the looming Brexit. This has put a strain on public housing resources at national and local levels. Allocation, therefore of the scarce housing resources needs to be streamlined and effective. However, the allocation of the scarce housing resources at the start requires carefully defined needs and demand framework for housing to be in place. Moreover, the prospect of sustained cuts to the availability of public funding, in part, imposed by the UK government is more the reason to have an effective housing needs and demand framework or system. Equally, the Scottish government mentions that the framework for housing delivery should cater for the variety of needs and demands that offers differing tenures and flexible transitions between tenures, helping to enhance economic growth and social mobility, as well as strengthening communities in the process. To cater for these needs and demands, there has to be a mechanism that identifies them in the first place. The right identification of these needs and demands is a key first step to enhancement of economic growth and social mobility.

Gibb and Leishman (2011) argue that there is ambiguity in the criteria for housing needs measure i.e., regeneration, homelessness and affordability used as the criteria. Each of the three according to Gibb and Leishman (2011), suggest quite different understanding of need and demand due to differing geographical need and thereby impacting on spatial allocation of resources. To this end, the Scottish government through the Centre of Housing Market Analysis (CHMA) developed guidelines or framework for housing need and demand assessment to enable local authorities met the Housing (Scotland) Act 2001. The Act requires local authorities to underpin their Local Housing Strategy (LHS) with an assessment of housing need and demand. The framework known as Housing Needs and Demand Assessment (HNDA) is thus meant to help local authorities in Scotland provide the evidence base for local strategies (Shelter Scotland 2015). The HNDA framework according to Scottish Government (2015) underpins the following key areas of housing policy and planning:

- Housing Supply Target (HST) - to inform the setting of a HST for use in the Local Housing Strategies (LHS) and Development Plan (LDP). The HST sets out the amount and type of housing to be delivered over the period of both plans,

- Stock Management - to assist understanding of the current and future demand for housing by size, type, tenure and location in order to optimise the provision, management and use of stock. This in turn feeds into policy and planning decisions about future stock in the LHS,

- Housing Investment - to inform future housing investment decisions, for example through Strategic Housing Investment Plans (SHIPs), 
- Specialist Provision - to inform the provision and use of specialist housing and housing-related services to enable independent living for all, as expressed in policy in the LHS and to inform planning decisions e.g. land for gypsy/travellers,

- Geographic distribution of land - to inform the spatial allocation of land through the Development Plan for new housing at both Housing Market Area level and Local Authority level.

Based on the outcomes and projections of the HNDA, the Scottish Government, for example, has plans to deliver at least 50,000 affordable homes by 2021 backed by a spend of over $£ 3$ billion. Clearly, the HNDA framework is critical to both local authorities and the Scottish government. Getting it right has far reaching implications on communities in Scotland.

While the HNDA framework was devised to aid in ascertaining or assessing estimates of housing need and demand that are subsequently used in the deriving of local and national targets, literature reviewed suggest a split in opinions by practitioners of the effectiveness of the framework. Since its inception, limited research on the HNDA framework effectiveness has been done. However, limited literature such as Powell et al (2015), suggest that opinions differ among practitioners on whether the HNDA has been a success. Using a qualitative approach, Newhaven (2015) suggests various limitations in the HNDA framework amongst others include: the lack of clarity on the role and purpose of housing need and demand assessment; the lack of clarity on the scope of the definition of housing need to be adopted locally thus leading to these local authorities not necessarily measuring the same thing; the lack of clarity on how to proceed with assessing the housing-related needs of different sections of the community outlined in the framework; the lack of clarity on whether housing market areas should provide only or the most appropriate spatial basis for assessing housing need, or how to disaggregate estimates within and across housing market areas when assessing need in terms of housing market areas; etc.

It is not clear from the limited available literature whether or not the HNDA framework accurately determines the housing needs for Scotland (Scottish local authorities) or indeed whether or not the framework for measuring housing need and demand such as the HNDA framework is robust enough and has been effective. As a result of the issues highlighted, this study sought to evaluate the effectiveness of the HNDA framework in Scottish Local Authorities by highlighting those factors that have been effective in the framework in light of current trends and shifting events on the ground in housing market in Scotland. The organization of the paper is as follows. In the first three sections a review of literature on the concept of housing need in Scotland, offering a historic perspective and a general outline of Housing Need and Demand Assessment Framework in Scotland is given. The section that follows, reviews the effectiveness in projects outlining the HNDA framework. The subsequent section then presents the analysis of the HNDA Framework effectiveness factors. The final section is devoted to conclusions and future research directions.

\section{The Concept of Housing Need in Scotland - A Historic Perspective}

In the early 1970, the Scottish Development Department convened a working party on housing needs (Newhaven Research (2015). The working party concluded that there was a strong case for the adoption of a comprehensive approach to housing needs assessment by Scottish local authorities (Scottish Housing Advisory Committee, 1972). The working party further concluded that local authorities should be aware of the totality of the housing needs of 
its area. Without this knowledge, it would be very difficult for local authorities to come to an informed decision on what its policy should be. Furthermore, the Scottish Development Department (1977) published a detailed operational guidance for housing need which put the matter plainly than in the past were the assessment of housing need had been regarded mainly as an assessment of the need for new building and the need for new buildings had been seen largely in terms of new local authority building. However, the objective of a housing needs study required a comprehensive approach to the assessment of housing needs. Over the 1980s, however, most Scottish local authorities showed little enthusiasm for responding to this agenda (Newhaven Research, 2015). The establishment of Scottish Homes in 1989 led to a re-engagement with the issue of comprehensive needs assessment and for instance, in 1993, it produced a guide to local housing system analysis (LHSA), initially intended for internal use. This guide was then revised and updated twice for local authorities (Maclennan et al, 1998; O'Sullivan et al, 2004).

The Scottish Government also sought to tradeoff the net requirement for new affordable housing across Scotland directly through a series of commissioned studies (School of Planning and Housing, 2001; Bramley, 2003; Bramley, 2004; Bramley et al, 2006). The approaches employed in these studies reflected the analytical framework for needs assessment embedded within the Department of the Environment, Transport and the Regions guidance on assessing local housing need published in 2000 (Bramley et al, 2000). However, whereas the latter guidance assumed that the need calculations would be informed by local household surveys, the modelling commissioned by the Scottish Government had relied on secondary data sources. Newhaven Research (2015) states that the authors of these studies were careful to point out that housing is a complex and multi-dimensional issue and that the estimates generated do not provide a complete picture of housing need. Years on, the issues surrounding housing need still dominate the political and social landscape. For example, Shelter Scotland (2015) note that recently the Scottish government had expressed a commitment to deliver at least 30000 affordable homes, of which at least 2 thirds will be for social rent, including 5000 houses year on year. This equates to around 6000 affordable homes per year over five years. This is on the back of the Scottish housing system experiencing significant change and pressure over many years (Shelter Scotland, 2015). Households have found it difficult to realize their long-term aspirations towards home ownership and social lettings have become more concentrated among the poorest and most vulnerable sections of the society. Thus, housing supply remains a stated priority for the Scottish government.

\section{Housing Need and Demand Assessment Framework in Scotland}

This section sets out the framework for assessing affordable housing need in Scotland. It focuses in particular on the housing planning framework, illustrating how the evidence from the Housing Need and Demand Assessment (HNDA) framework relates to Local Housing Strategies (LHSs). This section also highlights the features of the Housing Need and Demand Assessment (HNDA) framework.

\section{The Scottish Housing Planning Framework}

As mentioned earlier, in Scotland, section 89 of the Housing (Scotland) Act 2011 entitles Ministers to require a local authorities to carry out an assessment of housing need and 
demand while Scottish policy on land use directs that the preparation of Local Housing Strategies (LHS) and development plans should be closely aligned and supported by an assessment of housing need (Scottish Government 2015). The LHS being a pivotal document that reflects local authorities' strategic housing role and statutory responsibilities. It is developed in partnership with public, private and voluntary sector agencies (Scottish Government 2014; Powell, et al, 2015). The HNDA framework serves to provide that housing need assessment. Furthermore, the Town and Country Planning (Scotland) Act 1997 (as amended), requires Local and Strategic Planning Authorities to plan for land use in their area, including the allocation of land for housing. The HNDA framework evidence also supports this process. Figure 1 illustrates how the HNDA, LHS and LDP align in practice.

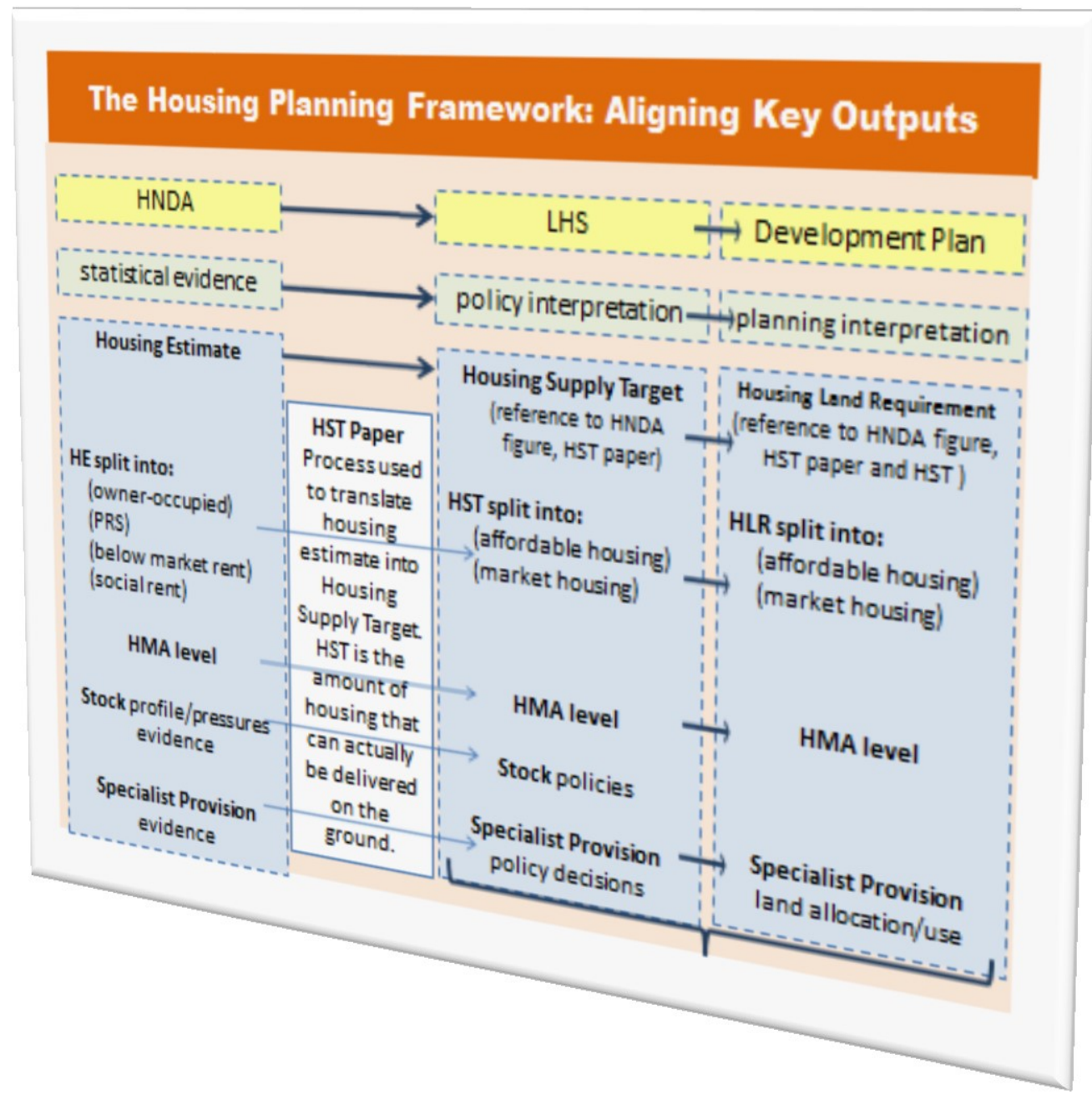

Figure 1: Housing Planning Framework (Source: Scottish Government, 2018)

\section{Housing Need and Demand Measure in Scotland}

The HNDA framework arrives at estimates for the number of additional homes, including affordable and specialist housing, required to meet current and future need and demand (Scottish Government, 2014) as follows and as illustrated in Table 1.0:

- Current need: driven by such factors as pressures on existing stock including overcrowding, homelessness, care and support needs etc. 
- Future need: driven by future household projections training. The amount of additional housing to be delivered is outlined in the Housing Supply Target.

Table 1.0: Summary of Scottish Government housing needs framework (Adapted from Powell et al, 2015)

\begin{tabular}{l|l|l|}
\cline { 2 - 3 } Steps & \multicolumn{2}{|c}{} \\
\hline $\mathbf{1}$ & & Count of households in backlog need \\
\hline $\mathbf{2}$ & Minus & Existing stock to meet housing need \\
\hline $\mathbf{3}$ & Equals & Net current need \\
\hline $\mathbf{4}$ & Divided $\boldsymbol{b y}$ & Backlog reduction period (10years) \\
\hline $\mathbf{5}$ & Equals & Annual quota of households in current need \\
\hline $\mathbf{6}$ & Plus & Annual number of new households in need \\
\hline $\mathbf{7}$ & Plus & Annual number of existing households falling into need \\
\hline $\mathbf{8}$ & Minus & Annual affordable supply \\
\hline $\mathbf{9}$ & Equals & Estimate of annual housing need \\
\hline
\end{tabular}

Powell et al (2015) state that each of the nine steps shown in Table 1.0, highlights aspects articulated in the official framework (guidance) and illustrate each step as follows:

\section{- Step 1: Count of households in need backlog}

The first step is to calculate the number of households whose current housing circumstances fall below minimum accepted standard. As part of the backlog need calculation, Local Authorities are expected to discount households that have sufficient income to secure a market solution to their housing needs as well as households for whom year in-situ solution would be appropriate or preferred. The framework gives a reasonably clear steer on how to assess whether a household can afford a market solution.

\section{- Step 2: Existing stock to meet housing need}

Whilst existing social tenants in need should be included in the count of backlog need, the dwellings they occupy should be "netted off" at Step 2. This implies that existing social tenants (other than concealed households subsumed with the households of a social tenant) will have their housing need resolved by moving within the social sector. So the net effect on the overall balance of affordable housing is zero.

\section{- Steps 3 to 5: Converting net current need into a flow}

Step 3 requires Local Authorities have an estimate of net current housing need. The framework assumes the net current housing need figure will be amortised over a specified period of time (steps 4 and 5). Local Authorities therefore need to decide by what proportion this backlog pool could be realistically reduced each year.

\section{- Steps 6 and 7: Future need}

Future need (also referred to as newly arising need) has two components:

- newly forming households in need and

- existing households falling into need. 
To identify new households unable to enter the private housing market (step 6), an estimate of the number of new households likely to form each year to match their income and profiles to entry-level house prices gold private rents is made .

Turning to existing households falling into need (step 7), the framework suggests estimating as the basis for projecting the annual flow of households that have applied and been rehoused within a year.

\section{- Step 8: Affordable housing supply}

Turning to the supply side of the calculation, the guidance framework directs that allowance be made for the planned supply of new affordable units. This potentially refers to new units in development or the number of units outlined in strategic housing investment plans

\section{- Step 9: Estimate of net annual housing need}

The final step in the calculation is to combine the supply and need calculations to quantify a potential shortfall or surplus in affordable housing supply. In applying the framework, Local Authorities are expected to corroborate statistics used to populate the housing need model with evidence from other sources.

\section{Effectiveness in Projects - The case of the HNDA Framework}

The Oxford English Dictionary defines a project as being a plan, a scheme, or a course of action. Borjeson (1976) defines a project as a temporary activity with defined goals and resources of its own, delimited from but highly dependent upon the regular activity. Morris and Hough (1987) define a project as an undertaking to achieve a specified objective, defined usually in terms of technical performance, budget and schedule. Therefore, a project is the "investment of resource for return", where the investment is defined as being financial, manpower and/or material and the return being a commercial or social benefit. These are useful definitions, as they do not restrict the project to any particular sector. The essence of these definitions is the recognition that the investment in a project is undertaken to add value to the core business of a client. The project has by definition a start date, a completion date, resources for its undertaking, a method for its smooth integration into the core business and ideally performance indicators which allow its impact on the core business to be measured.

Kenny (2003) states that when judging a project's success within an organization, one must take into account the project's effectiveness in contributing to the organization's strategic objectives. Jugdev and Müller (2005) further indicated that, project management as a concept is established to optimize projects' effectiveness. Effectiveness means achieving the project's goals and objectives. To Dweiri and Kablan (2006), effectiveness is measured or evaluated as a function of the degree to which project goals are achieved. Patah (2010) argues that project success is related effectiveness. The success of any project is determined by how well the project contributes to the achievement of the organization's strategic objectives (effectiveness).

In the local authority context, processes can be regarded as projects as they portray characteristics of projects. These processes as with the case with any other type of project in any other sector are used on a daily basis to achieve organisational or indeed in this case local authority strategic goals. For instance, in the public sector an investment of resources. i.e., 
manpower, material or finance can be made into a process such as the HNDA framework. A return from this investment in this case can be in the form of commercial or social benefits. Additionally, the processes, the HNDA framework included, have a start and completion date. Furthermore, these processes, like projects have key indicators that allow their impact on the local authority and communities to be measured. Thus, the translation of local authority goals and strategies relies on the success of the process or projects. In this regard, the HNDA framework is regarded as a project in this paper as it has all the hallmarks of a project. To be effective and meet stated goals and objectives, the Scottish government and indeed Local authorities should recognise the HNDA framework as a project and effort must be made to recognise factors that that have either been effective or otherwise in the framework. Thus, when judging the HNDA framework's success, one must take into consideration its contribution towards achieving Scottish Local Authority goal of effectively measuring housing need and demand. The HNDA framework in this case is like any other project and therefore is a way to implement local authority strategies. Consequently, the HNDA framework's objective must directly be aligned to Local Authority's strategic objective. The effectiveness of the HNDA framework should hence be determined by how well it contributes to the achievement of the strategic objectives of Local Authorities. In order to determine effectiveness in this study, several factors that contribute to project effectiveness were contextualized within the HNDA framework with the goal of ascertaining its effectiveness for local authorities in Scotland.

\section{Methodology}

The first stage in this study was to review of literature, drawing out effectiveness factors in projects which are then contextualised within the Housing need and demand assessment framework in Scotland. The intention in the study in this paper was to measure how these factors have been effective in the HNDA framework was conducted via a questionnaire survey to get the view from practitioners in Scottish Local Authorities. Perspective of the HNDA framework was gathered from all 32 local authorities in Scotland.

\section{Overview of the Analytical Framework}

In order to evaluate the effectiveness of the HNDA framework, all 32 local authorities in Scotland were approached. The local authorities included those listed in Table 2.

\section{Table 2: Scottish Local Authority Districts Approached}

\begin{tabular}{ll}
\hline Scottish Local Authority Districts & \\
\hline Aberdeen City & Highland \\
Aberdeenshire & Inverclyde \\
Angus & Midlothian \\
Argyll \& Bute & Moray \\
Edinburgh, City of & North Ayrshire \\
Clackmannanshire & North Lanarkshire \\
Dumfries \& Galloway & Orkney \\
Dundee City & Perth \& Kinross \\
East Ayrshire & Renfrewshire \\
East Dunbartonshire & Scottish Borders, The \\
East Lothian & Shetland \\
\hline
\end{tabular}




\begin{tabular}{ll}
\hline East Renfrewshire & South Ayrshire \\
\hline Eilean Siar & South Lanarkshire \\
Falkirk & Stirling \\
\hline Fife & West Dunbartonshire \\
Glasgow City & West Lothian \\
\hline
\end{tabular}

An email with the research questionnaire was sent out. A total of 20 local authorities returned the questionnaires at the cut-off date. This represented a total response rate of $66 \%$. In terms of individual respondents, the following Table 3.0 shows the number in each category.

Table 3.0: Cross Section of Respondents

\begin{tabular}{lc}
\hline Respondents & Number \\
\hline Housing Services Managers & 2 \\
Senior Planners & 3 \\
Strategic Planners & 9 \\
Housing Strategic Managers & 3 \\
Policy Planners & 3 \\
Total & $\mathbf{2 0}$ \\
\hline
\end{tabular}

Table 4.0 also categorises the respondents (participants) in terms of experience in working with the HNDA framework.

Table 4.0 : Role of Participant HNDA Framework Experience

\begin{tabular}{|c|c|c|c|c|c|c|}
\hline & & \multicolumn{4}{|c|}{ Participant HNDA Experience } & \multirow[b]{2}{*}{ Total } \\
\hline & & $>20$ & $11-15$ & $6-10$ & $0-5$ & \\
\hline \multirow[t]{5}{*}{ Role of Participant } & Housing Services Manager & 0 & 1 & 1 & 0 & 2 \\
\hline & Senior Planner & 0 & 1 & 2 & 0 & 3 \\
\hline & Strategic Planner & 0 & 0 & 9 & 0 & 9 \\
\hline & Housing Strategic Manager & 1 & 0 & 1 & 1 & 3 \\
\hline & Policy Planner & 0 & 1 & 1 & 1 & 3 \\
\hline Total & & 1 & 3 & 14 & 2 & 20 \\
\hline
\end{tabular}

The questionnaire used in this research comprised of two parts. The first sought to obtain information about the background of the respondents, such as experience, role in the local authority they represent. The second part highlighted 18 HNDA framework effectiveness factors from literature. Respondents were required to classify in terms of agreement the level of effectiveness of each factor. The classification contained five alternatives that indicated the level of agreement attributed to each effective factor identified from literature. Thus, using the scale of 1, strongly disagree to 5, strongly agree, respondents were asked rank the effectiveness of each factor in the HNDA framework as used by your Local Authority. 
Furthermore, the analysis of the research data was done using the SPSS statistical software to address the issue of the reliability of the data used in this research.

\section{Reliability using Cronbach's Alpha ( $\alpha$ ) in SPSS}

Before the analysis was conducted, the reliability testing using Cronbach's Alpha Coefficient was conducted. The Cronbach's Alpha ( $\boldsymbol{\alpha}$ ) was used to measure the internal consistency (reliability) of the data. This test was run to determine whether the questions in the questionnaire all reliably measured with the same latent variable (effectiveness factors of the HNDA framework). The test was run on all questions in the questionnaire. The results are illustrated in the Tables 5.0 below.

\section{Table 5.0: Reliability of the HNDA Effectiveness Data}

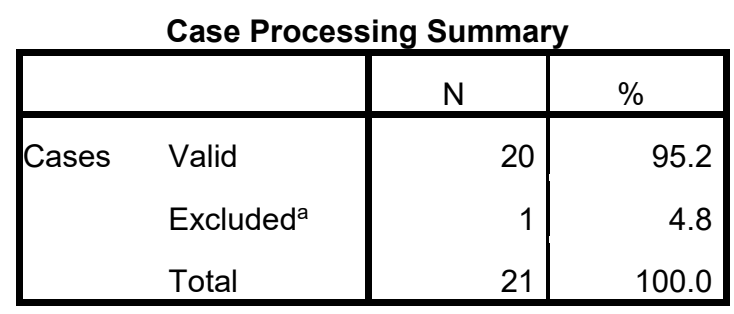

a. Listwise deletion based on all variables in the procedure.

Reliability Statistics

\begin{tabular}{|r|r|}
\hline Cronbach's Alpha & N of Items \\
\hline .903 & 18 \\
\hline
\end{tabular}

From this test, it can be seen that Cronbach's Alpha is 0.903 , which also indicates a high level of internal consistency the sample used.

The Likert Scale was used to code and measure the results. As mentioned before, a total of 20 valid questionnaires representing a return of $66 \%$ of the distributed questionnaire and these were subsequently analysed. Data collection was carried out using a single set of questionnaire for all respondents. The analysis involves summarising the data collected to obtain results and communicate the findings.

\section{Findings}

Findings on the effectiveness factors on the existing HNDA framework identified from literature and are illustrated in Table 6.0.

Table 6.0: Effectiveness factors in the existing HNDA framework 
The approaches to defining and detailing housing need as a concept by the Scottish government in the HNDA framework

The approaches to defining and detailing the measurement mechanisms of housing need in the HNDA framework

The planning review control mechanisms set up in the HNDA process

The coordination of the HNDA framework activities

The communication channels and systems in place in the HNDA process

Mechanisms for the involvement and commitment of stakeholders - e.g Communities, partners in the HNDA process

The use of available information from historic HND Assessments

Local Authority organizational structure that supports the HNDA framework

The process for hiring of quality subcontractor services (Outsourcing work)

The identification mechanism of local community uniqueness in terms of size, geography in the HNDA process

The funding mechanism to completion of the HNDA framework

The time estimates set for completing HNDA process is realistic

Staff training (such as, data analysis, project management) stipulated in the HNDA framework

Project monitoring, control and feedback process in the HNDA framework

The use of appropriate technology in the HNDA framework

Furthermore, findings from the survey are also illustrated in this section and outline the respondent's professional view of the HNDA framework effectiveness.

\section{Background Information of the Questionnaire Respondents}

This section evaluates the background information of the respondents to assess their professional competence in the use of the HNDA framework. Table 7.0 outlines the role of participant and respective Local Authority experience while Table 8.0 shows the different Local Authority types in Scotland responded in this study.

Table 7.0: Role of Participant and Participant Local Authority Experience

\begin{tabular}{|c|c|c|c|c|c|c|}
\hline & & \multicolumn{4}{|c|}{ Participant Local Authority Experience } & \multirow[b]{2}{*}{ Total } \\
\hline & & $>20$ & $16-20$ & $11-15$ & $6-10$ & \\
\hline \multirow[t]{5}{*}{ Role of Participant } & Housing Services Manager & $50.0 \%$ & & $50.0 \%$ & & $100.0 \%$ \\
\hline & Senior Planner & $33.3 \%$ & $33.3 \%$ & $33.3 \%$ & & $100.0 \%$ \\
\hline & Strategic Planner & & & $100.0 \%$ & & $100.0 \%$ \\
\hline & Housing Strategic Manager & $33.3 \%$ & & $33.3 \%$ & $33.3 \%$ & $100.0 \%$ \\
\hline & Policy Planner & $66.7 \%$ & & $33.3 \%$ & & $100.0 \%$ \\
\hline Total & & $25.0 \%$ & $5.0 \%$ & $65.0 \%$ & $5.0 \%$ & $100.0 \%$ \\
\hline
\end{tabular}


Table 8.0: Local Authority Type

\begin{tabular}{|l|r|r|r|r|}
\hline & Frequency & Percent & Valid Percent & $\begin{array}{c}\text { Cumulative } \\
\text { Percent }\end{array}$ \\
\hline Metropolitan & 9 & 45.0 & 45.0 & 45.0 \\
District Council & 2 & 10.0 & 10.0 & 55.0 \\
Scottish Unitary Authority & 6 & 30.0 & 30.0 & 85.0 \\
Rural Authority & 2 & 10.0 & 10.0 & 95.0 \\
Island Authority & 1 & 5.0 & 5.0 & 100.0 \\
Total & 20 & 100.0 & 100.0 & \\
\hline
\end{tabular}

Table 9.0: Role of Participant and Participant HNDA Experience

\begin{tabular}{|c|c|c|c|c|c|c|}
\hline & & \multicolumn{4}{|c|}{ Participant HNDA Experience } & \multirow[b]{2}{*}{ Total } \\
\hline & & $>20$ & $11-15$ & $6-10$ & $0-5$ & \\
\hline \multirow[t]{5}{*}{ Role of Participant } & Housing Services Manager & & $50.0 \%$ & $50.0 \%$ & & $100.0 \%$ \\
\hline & Senior Planner & & $33.3 \%$ & $66.7 \%$ & & $100.0 \%$ \\
\hline & Strategic Planner & & & $100.0 \%$ & & $100.0 \%$ \\
\hline & Housing Strategic Manager & $33.3 \%$ & & $33.3 \%$ & $33.3 \%$ & $100.0 \%$ \\
\hline & Policy Planner & & $33.3 \%$ & $33.3 \%$ & $33.3 \%$ & $100.0 \%$ \\
\hline Total & & $5.0 \%$ & $15.0 \%$ & $70.0 \%$ & $10.0 \%$ & $100.0 \%$ \\
\hline
\end{tabular}

The tables represent respondents' years of experience. From Table 7.0, 5\% of the respondents had 16 to 20 years of professional working experience while $\%$ of the respondent had 11 to 15 years' experience. Similarly, $65 \%$ of the respondents had 1 to 6years experience working with the in public housing. $25 \%$ had more than 20 years' experience. These finding clearly show that the majority of the respondents have adequate professional work experience which indicate that the data obtained from the respondents is reliable. There is also a fair representation across various geographical location of Local Authorities as illustrated in Table 8.0. Respondent's level of involvement in the HNDA framework is presented in Table 9.0. It is evident from Table 9.0, that all respondents are actively involved in the use of the HNDA framework in Scotland. Purposive sampling method was adopted to arrive at this. The respondents who work or are most likely to work with the HNDA framework were targeted. These results therefore indicate that the information obtained from the respondents is reliable and adequate for the analysis.

\section{Effectiveness factors Frequency Ranking Analysis}

The initial task was to rank the effective statements according to various categories of agreement or disagreements. The results are shown Table 10.0. The ranking is done by sorting the effectiveness statements according to the frequency of the responses received. 
Table 10.0: HNDA Effectiveness Ranking

\begin{tabular}{|c|c|c|c|c|c|c|c|c|c|c|}
\hline & Strongly disagree & Ranking & Disagree & Ranking & Neutral & Ranking & Agree & Ranking & Strongly Agree & Ranking \\
\hline & Count & & Count & & Count & & Count & & Count & \\
\hline Scot Govt HNDA Implementation Financial Support & 0 & 2 & 0 & 4 & 4 & 6 & 6 & 7 & 10 & 1 \\
\hline Local Authority HNDA Support & 0 & 2 & 0 & 4 & 5 & 5 & 5 & 8 & 10 & 1 \\
\hline HNDA Goal Definition & 0 & 2 & 0 & & 3 & 7 & 17 & 2 & 0 & \\
\hline Housing Need Concept Definition in the HNDA & 0 & 2 & 1 & 3 & 4 & 6 & 14 & 4 & 1 & 3 \\
\hline HNDA Measurement Mechanism & 0 & 2 & 1 & 3 & 6 & 4 & 13 & 5 & 0 & 4 \\
\hline HNDA Planning Review Mechanisms & 0 & 2 & 1 & 3 & 5 & 5 & 14 & 4 & 0 & 4 \\
\hline HNDA Coordination Activities & 0 & 2 & 0 & 4 & 2 & 8 & 18 & 1 & 0 & 4 \\
\hline HNDA Communication Channels & 0 & 2 & 0 & 4 & 5 & 5 & 15 & 3 & 0 & 4 \\
\hline HNDA Community/Partner Involvement Mechanisms & 0 & 2 & 2 & 2 & 16 & 2 & 2 & 11 & 0 & 4 \\
\hline Use of HNDA Historic Information & 0 & 2 & 0 & 4 & 17 & 1 & 3 & 10 & 0 & 4 \\
\hline Local Authority Organisation Structure & 0 & 2 & 1 & 3 & 4 & 6 & 15 & 3 & 0 & 4 \\
\hline The Process of Outsourcing HNDA Work & 0 & 2 & 3 & 1 & 17 & 1 & 0 & 12 & 0 & 4 \\
\hline Identification of Community Uniqueness in the HNDA Process & 1 & 1 & 2 & 2 & 11 & 3 & 4 & 9 & 2 & 2 \\
\hline HNDA Funding Mechanism & 0 & & 3 & 1 & 5 & 5 & 11 & 7 & 1 & 3 \\
\hline Setting HNDA Time Estimate to Completion & 0 & 2 & 2 & 2 & 5 & 5 & 12 & 6 & 1 & 3 \\
\hline Staff Training & 0 & 2 & 2 & 2 & 5 & 5 & 13 & 5 & 0 & 4 \\
\hline Project Monitoring \& Control in the HNDA & 0 & 2 & 1 & 3 & 4 & 6 & 15 & 3 & 0 & 4 \\
\hline
\end{tabular}




\begin{tabular}{|c|c|c|c|c|c|c|c|c|c|c|}
\hline & Strongly Agree & Ranking & Agree & Ranking & Neutral & Ranking & Disagree & Ranking & $\begin{array}{l}\text { Strongly } \\
\text { disagree }\end{array}$ & Ranking \\
\hline & Count & & Count & & Count & & Count & & Count & \\
\hline Use of Technology in HNDA Process & 0 & 2 & 0 & 4 & 6 & 4 & 14 & 4 & 0 & 4 \\
\hline ScotGovt HNDA Implementation Financial Support & 10 & 1 & 18 & 1 & 17 & 1 & 3 & 1 & 1 & 1 \\
\hline Local Authority HNDA Support & 10 & 1 & 17 & 2 & 17 & 1 & 3 & 1 & 0 & 2 \\
\hline $\begin{array}{l}\text { Identification of Community Uniqueness in the HNDA } \\
\text { Process }\end{array}$ & 2 & 2 & 15 & 3 & 16 & 2 & 2 & 2 & 0 & 2 \\
\hline Housing Need Concept Definition in the HNDA & 1 & 3 & 15 & 3 & 11 & 3 & 2 & 2 & 0 & 2 \\
\hline HNDA Funding Mechanism & 1 & 3 & 15 & 3 & 6 & 4 & 2 & 2 & 0 & 2 \\
\hline Setting HNDA Time Estimate to Completion & 1 & 3 & 14 & 4 & 6 & 4 & 2 & 2 & 0 & 2 \\
\hline HNDA Goal Definition & 0 & 4 & 14 & 4 & 5 & 5 & 1 & 3 & 0 & 2 \\
\hline HNDA Measurement Mechanism & 0 & 4 & 14 & 4 & 5 & 5 & 1 & 3 & 0 & 2 \\
\hline HNDA Planning Review Mechanisms & 0 & 4 & 13 & 5 & 5 & 5 & 1 & 3 & 0 & 2 \\
\hline HNDA Coordination Activities & 0 & 4 & 13 & 5 & 5 & 5 & 1 & 3 & 0 & 2 \\
\hline HNDA Communication Channels & 0 & 4 & 12 & 6 & 5 & 5 & 1 & 3 & 0 & 2 \\
\hline HNDA Community/Partner Involvement Mechanisms & 0 & 4 & 6 & 7 & 5 & 5 & 0 & 4 & 0 & 2 \\
\hline Use of HNDA Historic Information & 0 & 4 & 11 & 7 & 4 & 6 & 0 & 4 & 0 & 2 \\
\hline Local Authority Organisation Structure & 0 & 4 & 5 & 8 & 4 & 6 & 0 & 4 & 0 & 2 \\
\hline The Process of Outsourcing HNDA Work & 0 & 4 & 4 & 9 & 4 & 6 & 0 & 4 & 0 & 2 \\
\hline Staff Training & 0 & 4 & 3 & 10 & 4 & 6 & 0 & 4 & 0 & 2 \\
\hline Project Monitoring \& Controlling the HNDA & 0 & 4 & 2 & 11 & 3 & 7 & 0 & 4 & 0 & 2 \\
\hline Use of Technology in HNDA Process & 0 & 4 & 0 & 12 & 2 & 8 & 0 & 4 & 0 & 2 \\
\hline
\end{tabular}


The statements which were most frequently chosen in each criteria (i.e Strongly Agree; Agree; Neutral; Disagree; Strongly disagree) were ranked first, followed by the second most frequently chosen factor. For example in the Strongly Agree category, Scot Govt HNDA Implementation Financial Support and the Local Authority HNDA Support statement was ranked $1^{\text {st }}$ as responded felt that these were the most effective. Note that the two factors had the same frequency of responses and therefore ranked the same. Various statements in this category received the least or no response. This way of ranking was done across all categories as can be seen in Table10.0.

The next stage in this ranking process was to then shuffle all rankings separately in the various categories according to the frequency of response starting with those with the highest to the least as illustrated in Table 11.0. From this table, it was then possible to identify those effective statements in which the respondents either agree or disagree. All those effective statements in the Strongly Agree category with frequency responses above 10 were ranked first. This was followed by those factors in the Agree category with the frequency responses above 10. This was then followed by the remaining effective statements in the Strongly Agree category and finally followed by those remaining effective statements in the Agree category. The other remaining criteria, such as the Neutral; Disagree and the Strongly disagree were not considered. By implication, the fact that an effective statement scores low in terms of frequency responses in the ranking, means that that effective statement is least considered and portray a disagreement on the part of the respondents. Thus, strongly disagree and disagree are effectively captured in the two categories analysed. The Neutral category is not considered as it deemed to fall either way of the analysis.

Table 11.0: The HNDA Framework Effectiveness Statements

\begin{tabular}{|l|c|c|}
\hline & & Ranking \\
\cline { 2 - 3 } HNDA Effectiveness Statements & Count & \\
\hline ScotGovt HNDA Implementation Financial Support & 10 & 1 \\
\hline Local Authority HNDA Support & 10 & 1 \\
\hline HNDA Coordination Activities & 18 & 1 \\
\hline HNDA Goal Definition & 17 & 2 \\
\hline HNDA Communication Channels & 15 & 3 \\
\hline Local Authority Organisation Structure & 15 & 3 \\
\hline Project Monitoring \& Controlling the HNDA & 15 & 3 \\
\hline Housing Need Concept Definition in the HNDA & 14 & 4 \\
\hline HNDA Planning Review Mechanisms & 14 & 4 \\
\hline Use of Technology in HNDA Process & 14 & 4 \\
\hline HNDA Measurement Mechanism & 13 & 5 \\
\hline Staff Training & 13 & 5 \\
\hline Setting HNDA Time Estimate to Completion & 12 & 6 \\
\hline ScotGovt HNDA Implementation Financial Support & 6 & 7 \\
\hline HNDA Funding Mechanism & 11 & 7 \\
\hline Local Authority HNDA Support & 5 & 8 \\
\hline Identification of Community Uniqueness in the HNDA Process & 4 & 9 \\
\hline
\end{tabular}




\begin{tabular}{|l|c|c|}
\hline Use of HNDA Historic Information & 3 & 10 \\
\hline HNDA Community/Partner Involvement Mechanisms & 2 & 11 \\
\hline The Process of Outsourcing HNDA Work & 0 & 12 \\
\hline Identification of Community Uniqueness in the HNDA Process & 2 & 2 \\
\hline Housing Need Concept Definition in the HNDA & 1 & 3 \\
\hline HNDA Funding Mechanism & 1 & 3 \\
\hline Setting HNDA Time Estimate to Completion & 1 & 3 \\
\hline
\end{tabular}

The next step was to delete those duplicate factors that in Table 12.0 to create a logical structured table with HNDA effective statements ranked from the highest in terms of the respondents perception to the least.

Table 12.0: The Refined HNDA Framework Effectiveness Statements

\begin{tabular}{|c|c|c|}
\hline \multirow[b]{2}{*}{ HNDA Effectiveness Statements } & \multirow[b]{2}{*}{ Count } & \multirow[t]{2}{*}{ Ranking } \\
\hline & & \\
\hline ScotGovt HNDA Implementation Financial Support & 10 & 1 \\
\hline Local Authority HNDA Support & 10 & 1 \\
\hline HNDA Coordination Activities & 18 & 1 \\
\hline HNDA Goal Definition & 17 & 2 \\
\hline HNDA Communication Channels & 15 & 3 \\
\hline Local Authority Organisation Structure & 15 & 3 \\
\hline Project Monitoring \& Control in the HNDA & 15 & 3 \\
\hline Housing Need Concept Definition in the HNDA & 14 & 4 \\
\hline HNDA Planning Review Mechanisms & 14 & 4 \\
\hline Use of Technology in HNDA Process & 14 & 4 \\
\hline HNDA Measurement Mechanism & 13 & 5 \\
\hline Staff Training & 13 & 5 \\
\hline Setting HNDA Time Estimate to Completion & 12 & 6 \\
\hline ScotGovt HNDA Implementation Financial Support & 6 & 7 \\
\hline HNDA Funding Mechanism & 11 & 7 \\
\hline Local Authority HNDA Support & 5 & 8 \\
\hline Identification of Community Uniqueness in the HNDA Process & 4 & 9 \\
\hline Use of HNDA Historic Information & 3 & 10 \\
\hline HNDA Community/Partner Involvement Mechanisms & 2 & 11 \\
\hline The Process of Outsourcing HNDA Work & 0 & 12 \\
\hline
\end{tabular}

In the refined Effective statements Table 12.0, for example, we see that "ScotGovt HNDA Implementation Financial Support" being ranked highly by the respondents while "Setting HNDA Time Estimate to Completion" being ranked the least in terms of effectiveness. Generally, across board, most of the respondents were highly appreciative of the HNDA framework. The responses in almost all cases were positive. However, after ranking the 
effective statements, there seems to be areas that need improvement or further investigation. For example, while the process of outsourcing was not found to be important relative to other in the earlier survey, in this case it is also the least in terms of effectiveness ranking. This implies that there is something amiss with outsourcing of HNDA work that perhaps could not be captured in this study. Another least ranking effective statement was the involvement of mechanisms of the community stakeholders. This is certainly an issues also raised in literature. Literature suggests that communities are not fully consulted or later play any critical role in the ascertainment of the need for housing nor is the issue of housing need fully understood by those that undertake the work.

\section{IMPLICATIONS, LIMITATIONS AND CONCLUSION}

This study has identified effectiveness factors inherent in the HNDA framework as used in Scottish Local Authorities. Findings from the study reveal the topmost ranking effectiveness factors in the Scottish Housing Need and Demand Assessment (HNDA) framework as including amongst others Scottish government HNDA implementation financial support; Local authority HNDA support; HNDA coordination activities; HNDA goal definition; HNDA communication channels; Local authority organisation structure; Project monitoring \& control in the HNDA. The least effective factors include: identification of community; uniqueness in the HNDA process; use of HNDA historic information; HNDA community/partner involvement mechanisms; the process of outsourcing HNDA work. The identification of the effectiveness factors in the HNDA framework in this research would go a long way in helping local authorities manage the housing need and demand assessment process in a consistent way. Those stakeholders within local authorities entrusted with project managing the HNDA framework would have a clear understanding of which factors within the framework have been effective and which have not. They will be in a position to prioritise those factors that have not been effective which then facilitate successful HNDA frameworks for local authorities. The prioritisation and identification of the effective factors would accelerate local authorities' housing need and demand assessment success achievement by faster removing the existing barriers in the HNDA framework thereby maximising effectiveness. This study is not without limitations. First, given the unique characteristics each particular Local authority has in Scotland, simply identifying effectiveness factors revealed in this research may not provide the an accurate representation of effectiveness of the HNDA framework implementation for specific local authorities as there are other variables at play in each local authority that may not necessarily be apparent in others. What the study has however done is to reveal ranked in terms of priority common effectiveness factors that applicable in all local authorities. Therefore, future studies may want to consider effectiveness factors qualitatively through interviewing experts in various departments in in specific local authorities. As no similar study has been carried out on effectiveness factors assessment in the HNDA framework in Scottish local authorities, the findings in this research contributes to literature on housing, thus highlighting the Scottish perspective. The study is a precursor to the mechanism for the housing need and demand identification and analysis in Scotland. 


\section{References}

Borjeson L., (1976) Management of project Work. The Swedish Agency for Administrative Development. Satskontoret, Gotab, Stockholm.

Bramley, G., Pawson, H., and Parker, J (2000) Local Housing Needs Assessment: A Guide to Good Practice, London: Department of the Environment, Transport and the Regions

Bramley, G. (2003) The Planning System and Affordable Housing in Scotland, in H. Pawson and W. Hayhurst, eds, Planning and the Delivery of Affordable Housing: What works? Built EnvironmentResearch Paper No 1, Edinburgh: Heriot-Watt University, School of the Built Environment.

Bramley, G. (2004) Local Housing Need and Affordability Model for Scotland - Update, Research, Report number 34, Edinburgh: Communities Scotland.

Bramley, G., Karley, N. K., \& Watkins, D. (2006) Local Housing Need and AffordabilityModel for Scotland - Update (2005-base). Report 72. Edinburgh: Communities Scotland.

Dweiri, F. T. \&Kablan, M. M. (2006).Using fuzzy decision making for the evaluation of project management internal efficiency. Decision Support Systems, 42, 712-726.

Gibb, K., and Leishman, C. (2011) Delivering Affordable Housing in Troubled Times: Scotland National Report. Project Report. Joseph Rowntree Foundation, York, UK.

Jugdev, K \& Müller, R. (2005).A retrospective look at our evolving understanding of project success. Project Management Journal, 36(4), 19-31.

Kenny, J. (2003). Effective project management for strategic innovation and change in organizational context.Project Management Journal, 34(1), 43-53.

Maclennan, D., More, A., O’Sullivan, A., and Young, G (1998) Local Housing System Analysis: Best Practice Guide, Edinburgh: Scottish Homes

Newhaven Research (2015), Wagging the Dog: Assessing housing need; Http://www.cih.org/scotland/policy/waggingthedog.pdf) Edinburgh: CIH Scotland

O’Sullivan, T., Young, G., Maclennan, D., Gibb, K., McLaren, J., Britain, A., Dowie, A., and Thornton, C (2004) Local Housing System Analysis Good Practice Guide, Edinburgh: Communities Scotland

Patah, L. A. (2010).[Evaluation of the relationship between the use of methods and training in project management and the success of projects through a contingency perspective: a quantitative analysis]. PhD in Production Engineering (Dissertation) -Universidade de São Paulo, São Paulo.

Powell R, Richard Dunning, Ed Ferrari, Kim McKee (2015) Affordable Housing Need in Scotland; Final Report - September 2015 
Scottish Development Department (1977) Scottish Housing Handbook: Assessing Housing Needs, A Manual of Guidance, Edinburgh: HMSO

Scottish Housing Advisory Committee (1972) Planning for Housing Needs; pointers towards a comprehensive approach: Report of the Working Party on Housing Needs, Edinburgh: HMSO

Scottish government (2010) Housing: Fresh Thinking, New Ideas - Summary; ISBN 9780 755994151 http://www.gov.scot/Publications/2010/06/25144849/0

Scottish Government (2014), Housing Need and Demand Assessment: A Practitioner's Guide. Edinburgh: Scottish Government.

Scottish Government, (2015), Housing need and demand Assessment (HNDA), A practitioner's Guide (2014) http://www.gov.scot/Resource/0045/00452652.pdf

Scottish Government, (2018) Housing Planning Framework (Source: http://www.gov.Scot/topics/built-environment/housing/supplydemand/chma/hnda/housingplanningdiagram)

School of Planning and Housing, 2001;) School of Planning and Housing (Edinburgh College of Art) in association with the Department of Building Engineering and Surveying (HeriotWatt University) (2001) The Role of the Planning System in the Provision of Housing, Edinburgh: Scottish Executive Central Research Unit.

Shelter Scotland (2015), Increasing investment in affordable homes; Capital Economics

The Homes Fit for the $21^{\text {st }}$ Century (2011) Homes Fit for the 21 st Century The Scottish Government's Strategy and Action Plan for Housing in the Next Decade: 2011-2020 ISBN: 978-0-7559-9920-0 